Peculiar fluted points were found ith other types in 1924 by Kenneth Casey) Jones of Mortlach on the urface of sand blows. They were so ifferent that $\mathrm{Mr}$. Jones prized them reatly. At that time, the Folsom oint was archaeologically unknown nd therefore was not described in ny literature. If Kenneth Jones had bund these points in situ as did Dr. iggins, Mortlach would probably ave been the name-not Folsom.

The Saskatoon point in the accomanying picture agrees nicely with ie average classic Folsom from the
Lendenmeier site. It was found accidentally in the summer of 1957 by a member of the Saskatoon Archaeological Society, but was not reported until the December meeting of the Society as the importance of the find was not realized. No associated material was noticed in the trench at at the time of the find. It was found about 12 inches below the present surface and some of the soil above appeared to have been disturbed previously. 'The Society will make an investigation of the site as soon as weather permits.

\title{
Folsom Fragment Found Near Woodrow
}

By A. J. Hudson, Mortlach

In the summer of 1957 I was so rtunate as to find a fluted flake ear the junction of Wood River and into Creek. If you examine the lustrations of this Folsom point you ill notice a difference in the fluting the two sides. The flake of the
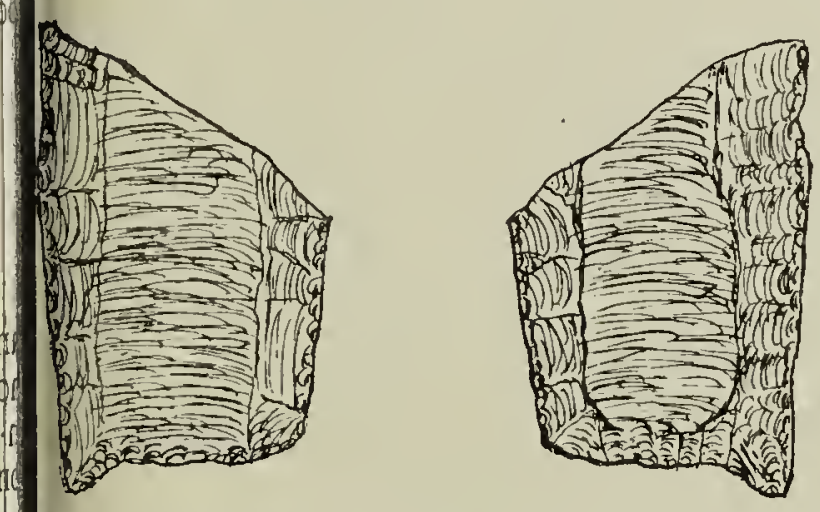

lsom fragment, chalcedony heavily patinated. Natural size.

side has been taken off from the se. In the process of making the int, the body is flaked on both les leaving a high central ridge and flat end at the base for a striking atform. I should guess that the ece must then be wedged in a block wood to get the proper resistances. mething in the form of a chisel ust have been used and a hard blow uck because of the need for curacy to get the first flake off. it with the flake on the reverse side difficulty arises. Unless the maker careful he is liable to break the int when striking off the second ig flake. In the present case, A2, striking platform has been made ward from the base and then the ke struck off. Finally a few thinig flakes have been taken out from base to bring the main flake scar sh with the base.
In the case of the two Folsom points owned by Mr. Conrad Dahl of Roseray. Saskatchewan, the problem has been met in a different way. One flake was taken out completely on one side, but on the cther side the flakes have been taken out piecemeal, i.e., a number of long, narrow flakes - safety first, so to speak. I examined Conrad Dahl's two Folsoms carefully one day and we decided that there was a strong possibility that the points were shaped after the fluting was done.. If the top end was left unfinished till the fluting was done, there would be less danger of shattering.

With the discovery of these Folsom points we're right on the trail of early man.

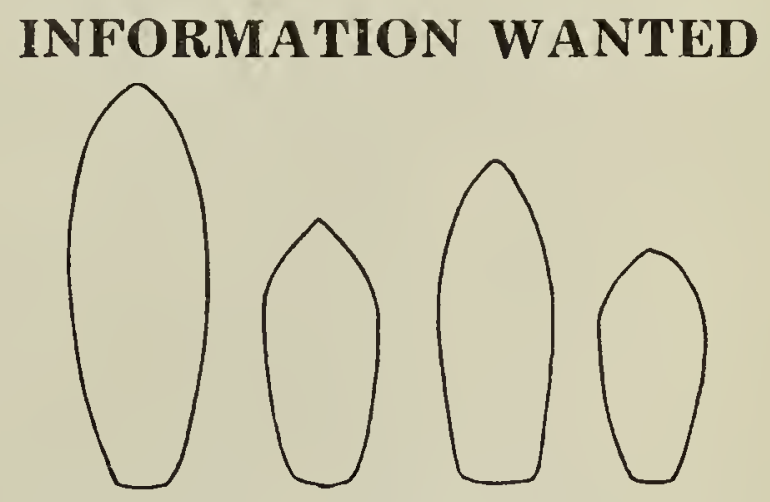

Information concerning the distribution of lanceolate projectile points in Saskatchewan and adjacent regions would be appreciated. The sketched outlines are of lanceolate points from the Parkhill site, south of Mcose Jaw, believed to be 7,000 to 8,000 years old. The largest point is just under three inches in length

Robert W. Nero,

Saskatchewan Museum of Natural History. 